\title{
Finite Earth
}

\author{
The world has agreed on 17 Sustainable Development Goals, to be adopted this week. This is great \\ progress towards acknowledging that the planet's finite resources need to be managed carefully in the \\ face of humanity's unlimited aspirations.
}

With globalization, the world has become smaller in our minds. But perhaps it has not become small enough to achieve sustainability. Everyone on the planet needs to feel part of one global community, tasked with managing limited goods and services from the environment in an equitable fashion. Yet for most individuals and businesses, at least in the developed world, the dominant mindset is still one of essentially unconstrained resources for those with enough cash in hand. This mindset needs to change. In a web focus on Sustainability on Earth (http://www.nature. com/ngeo/focus/sustainability-on-earth), we highlight Earth science themes that touch on key aspects of the Sustainable Development Goals that are due to be adopted in New York at the United Nations summit from 25 to 27 September.

Of the 17 Sustainable Development Goals (Table 1 in ref. 1), about half are closely linked to Earth science research. The new set of goals succeeds the eight United Nations Millennium Development Goals, whose main emphasis lay with health, equity and economic issues: only one goal was devoted to the environment. However, the role of diverse aspects of environmental health as a necessary condition for development and human well-being has come into focus over the 15-year lifetime of the Millennium Development Goals ${ }^{1}$. A range of environmental goals, including clean water, healthy terrestrial ecosystems and oceans, as well as urgent action on climate change, have therefore been included explicitly in the new set to reflect the insight that livelihoods and well-being depend to a large degree on intact natural systems. The points of intersection between the societal and natural goals are manifold and varied.

Pollution and public health are closely linked, for example. Outdoor air pollution has been estimated to cause between 1.6 and 4.8 million premature deaths every year globally, with a hotspot in Asia ${ }^{2}$. And air pollution is not limited to factory chimneys and car exhausts. Reductions in deforestation in Brazil since 2004 are implicated in preventing between 400 and
1,700 premature deaths of adults annually across South America ${ }^{3}$ : fires associated with deforestation had led to poor air quality during earlier periods of heavy deforestation, especially noticeable in non-drought years. When deforestation declined after 2004, the air became cleaner.

The diversity of natural-world impacts on humans is particularly visible in the vulnerability of coastal populations. Global sea-level rise is the most obvious risk for shoreline dwellers. But it is becoming increasingly clear that regional differences in the responses of sea level to melting ice and thermal expansion of the oceans are large. Assessing coastal vulnerability is yet more complicated, however. Shorter-term fluctuations in water levels, associated with storms and waves, are also important agents of erosion and surging. Coastal erosion in the Pacific Basin varies with the El Niño/Southern Oscillation ${ }^{4}$ - whose characteristics have been suggested to tend towards more frequent extreme events over the coming century ${ }^{5}$.

Finally, coastlines depend on sand and sediment supply. But a growing threat to shorelines comes from the global building boom: sand is an essential ingredient in concrete, and sand mining has become a highly profitable business. Some go so far as to suggest that sand should be viewed as an endangered natural resource ${ }^{6}$.

Even attempts at re-naturalization can go awry: the 'Grain for Green' project in China, initiated to restore the Loess Plateau to natural erosion rates and reduce the excessive sediment discharge of the Yellow River, may now be overshooting?

Coastlines as well as societies have always been in flux. Similarly, sustainability does not imply the prevention of change. But it does mean that humanity must eventually limit rates of consumption to the speed at which raw materials are regenerated. At the same time, waste production must be reduced to levels that can be safely disposed of, for very long timescales. This is an enormous task for all nations and all people.

Since the beginning of civilization, the number of trees on the globe has dropped

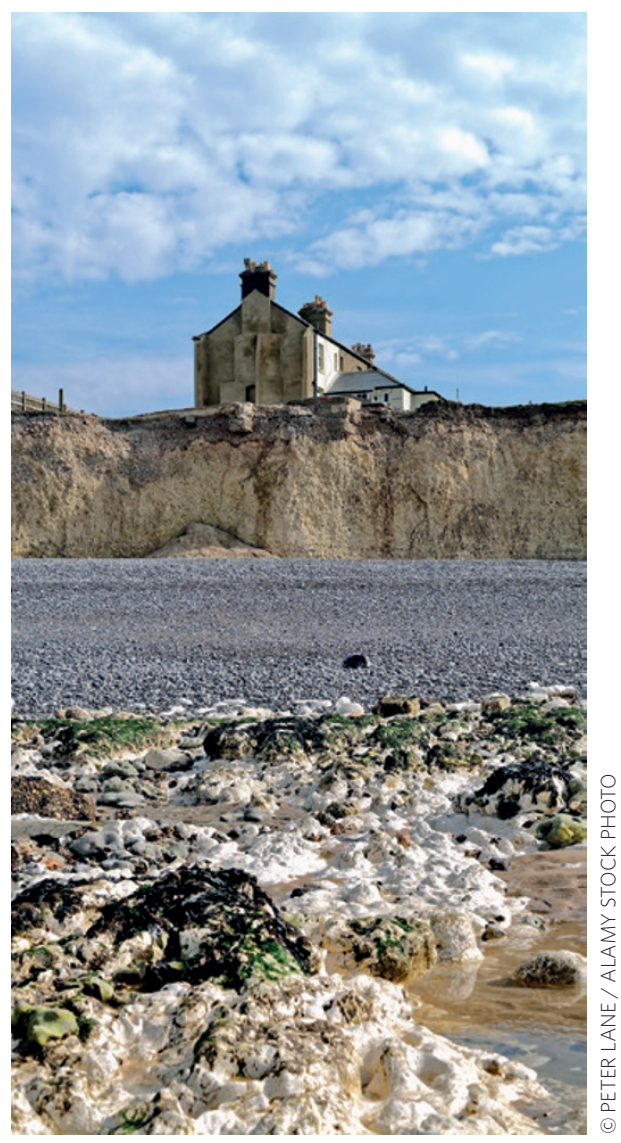

by almost half, to a total of about 3 trillion, and an estimated 15 billion more are cut every year ${ }^{8}$. As we are set to exhaust even resources as common as trees and sand, the notion that the planet is indeed finite must gain traction.

\footnotetext{
References

1. Lubchenco, J., Barner, A. K., Cerny-Chipman E. B. \& Reimer, J. N. Nature Geosci. 8, 741-745 (2015).

2. Lelieveld, J., Evans, J. S., Fnais, M., Giannadaki, D. \& Pozzer, A. Nature http://dx.doi.org/10.1038/nature15371 (2015).

3. Reddington, C. L. et al. Nature Geosci. 8, 768-771 (2015).

4. Barnard, P. et al. Nature Geosci. 8, 801-807 (2015)

5. Cai, W. et al. Nature Clim. Change 5, 849-859 (2015)

6. Gillis, J. R. Why sand is disappearing. The New York Times (4 November 2014); http://go.nature.com/OAgtcA

. Chen, Y. et al. Nature Geosci. 8, 739-741 (2015).

8. Crowther, T. W. et al. Nature http://dx.doi.org/10.1038/ nature14967 (2015).
}

Published online: 21 September 2015 